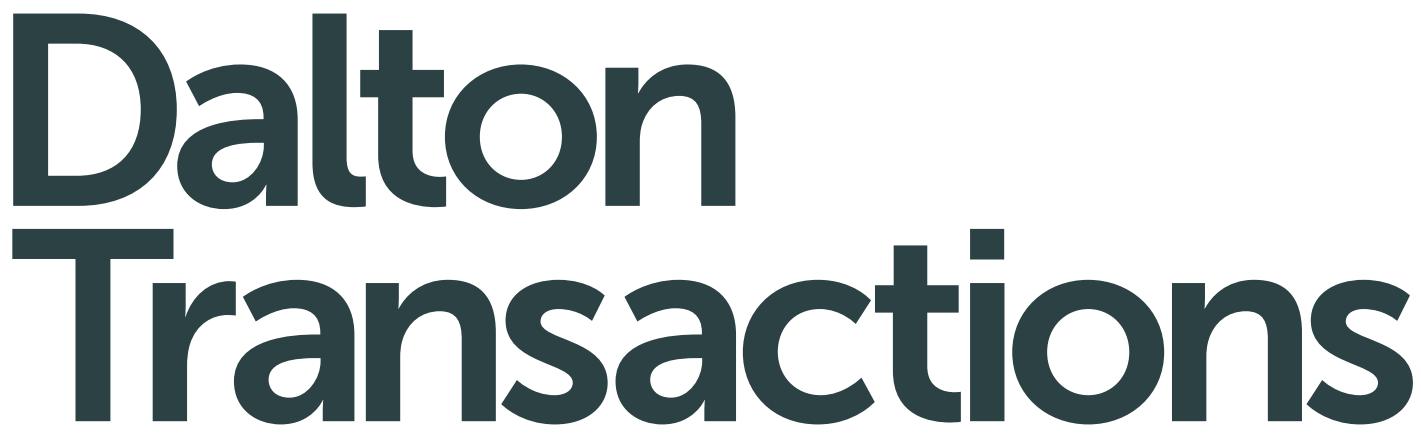

An international journal of inorganic chemistry

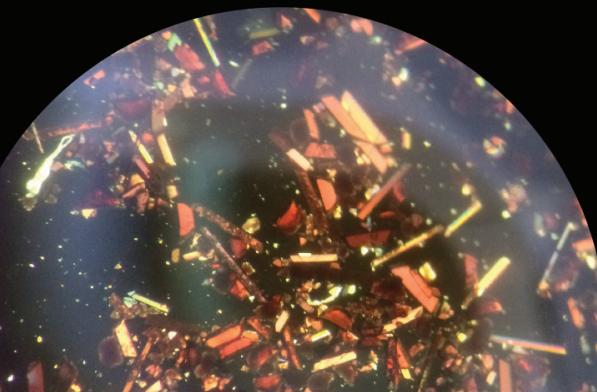

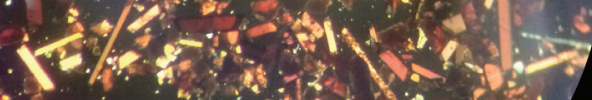

. . . .

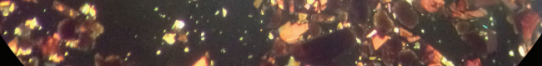

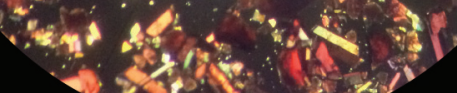

- 24 is 3

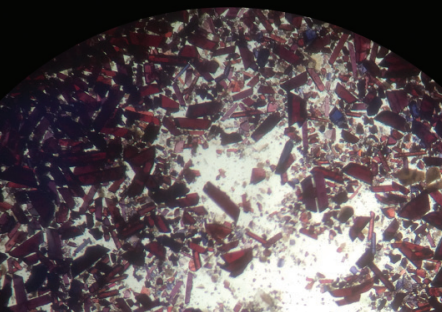

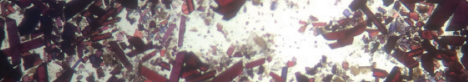

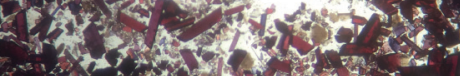

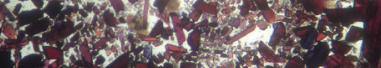

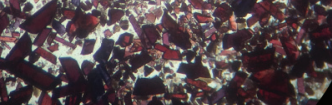

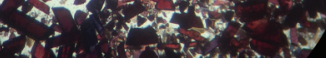

$$
3 \pi^{2}
$$

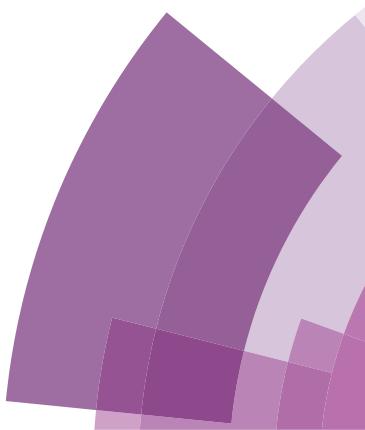




\section{(A) Check for updates}

Cite this: Dalton Trans., 2017, 46 7159

Received 3rd April 2017 Accepted 8th May 2017

DOI: $10.1039 / \mathrm{c} 7 \mathrm{dt} 01197 \mathrm{k}$ rsc.li/dalton

\title{
Magneto-structural correlations in a family of di-alkoxo bridged chromium dimers $\uparrow$
}

\author{
Hector W. L. Fraser, (D) a Gary S. Nichol, (D) a Gunasekaran Velmurugan, ${ }^{\text {b }}$ \\ Gopalan Rajaraman (D) ${ }^{b}$ and Euan K. Brechin (D)*a
}

\begin{abstract}
A series of di-alkoxo bridged $\mathrm{Cr}(\mathrm{III})$ dimers have been synthesised using pyridine alcohol ligands. The structures fall into four general categories and are of formula: $\left[\mathrm{Cr}_{2}(\mathrm{OMe})_{2}(\mathrm{pic})_{4}\right] \cdot \frac{1}{2} \mathrm{MeOH} \cdot \frac{1}{2} \mathrm{Et}_{2} \mathrm{O}$ (1), $\left[\mathrm{Cr}_{2}(\mathrm{hmp})_{2}(\mathrm{pic})_{2} \mathrm{X}_{2}\right]$ (where $\mathrm{X}=\mathrm{Cl}(\mathbf{2}), \mathrm{Br}(\mathbf{3})$ ), $\left[\mathrm{Cr}_{2}(\mathrm{~L})_{2} \mathrm{Cl}_{4}(\mathrm{~A})_{2}\right] \cdot 2 \mathrm{~S}$ (where $\mathrm{L}=\mathrm{hmp}, \mathrm{A}=\mathrm{H}_{2} \mathrm{O}$ and $\mathrm{S}=\mathrm{Et}_{2} \mathrm{O}(\mathbf{4})$; $\mathrm{L}=\mathrm{hmp}, \mathrm{A}=$ pyridine and $\mathrm{S}=$ pyridine (5); $\mathrm{L}=\mathrm{hmp}, \mathrm{A}=4$-picoline and no $\mathrm{S}(\mathbf{6}) ; \mathrm{L}=$ hep, $A=\mathrm{H}_{2} \mathrm{O}$ and $\mathrm{S}=\mathrm{MeCN}(\mathbf{7}))$, and $\left[\mathrm{Cr}(\mathrm{hmp})(\mathrm{hmpH}) \mathrm{Cl}_{2}\right] \cdot \mathrm{MeCN}(\mathbf{8})$. Direct current (DC) magnetic susceptibility measurements show relatively weak antiferromagnetic exchange interactions between the $\mathrm{Cr}(\mathrm{III})$ centres with $\boldsymbol{J}$ values $<|15| \mathrm{cm}^{-1}$ in all of the complexes measured. DFT calculations performed on complexes $\mathbf{1 - 8}$ reproduce both the sign and strength of the exchange interactions found experimentally, and confirm that the magnitude and sign of the $\mathrm{J}$ value is strongly dependent upon the orientation of the dihedral angle formed between the bridging $\mathrm{Cr}_{2} \mathrm{O}_{2}$ plane and the $\mathrm{O}-\mathrm{R}$ vector of the bridging group $(\theta)$, and the $\mathrm{Cr}-\mathrm{O}-\mathrm{Cr}-\mathrm{O}$ dihedral angle $(\psi)$.
\end{abstract}

\section{Introduction}

Since the late 1980 s the study of paramagnetic metal complexes has become a prolific area of research, with much focus on polymetallic $3 \mathrm{~d}$ clusters, initially dominated by the chemistry of $\mathrm{Mn}$ and $\mathrm{Fe}^{1-3}$ The coordination and structural chemistry of polynuclear $\mathrm{Cr}(\mathrm{III})$ cages by comparison is less well developed. This may be due to the lack of a metalloenzyme containing a polymetallic chromium compound, ${ }^{4,5}$ the relative kinetic inertness of the octahedral $\mathrm{d}^{3}$ ion and the requirement for elevated temperatures for reaction, the inherent stability of low nuclearity species, and the dominance of antiferromagnetic exchange between isotropic $s=3 / 2$ ions. $^{6}$ However, solution stability and slow ligand exchange can be manipulated to exert a degree of control over structure and postsynthetic reactivity that can be difficult for more labile $3 \mathrm{~d}$ ions. This, and the realisation that $\mathrm{Cr}$ cages may have potential application in quantum information processing, has seen a revival in $\mathrm{Cr}$ (III) cluster chemistry, resulting in the synthesis of

\footnotetext{
${ }^{a}$ EaStCHEM School of Chemistry, The University of Edinburgh, David Brewster Road, Edinburgh, EH9 3FJ, Scotland, UK. E-mail: E.Brechin@ed.ac.uk; Tel: +44 (0)131-650-7545

${ }^{b}$ Department of Chemistry, Indian Institute of Technology Bombay, Mumbai, 400076, India.E-mail: rajaraman@chem.iitb.ac.in

$\dagger$ Electronic supplementary information (ESI) available: Additional details for $\mathrm{X}$-ray crystallography and structure, magnetic measurements, and DFT data. CCDC 1482832-1482837 and 1540438-1540439. For ESI and crystallographic data in CIF or other electronic format see DOI: 10.1039/c7dt01197k
}

some beautiful new cages, possessing fascinating low temperature physics - perhaps best exemplified by the extensive family of homo- and heterometallic, even and odd numbered $\mathrm{Cr}$ (III) rings. ${ }^{7,8}$

The vast majority of $\mathrm{Cr}(\mathrm{III})$ clusters employ bridging carboxylate ligands; indeed for compounds of nuclearity three or more they appear in approximately $85 \%$ of deposited structures in the Cambridge Structural Database. Historically, the first of these were the ubiquitous oxo-centred triangles of general formula $\left[\mathrm{Cr}_{3} \mathrm{O}\left(\mathrm{O}_{2} \mathrm{CR}\right)_{6}\left(\mathrm{H}_{2} \mathrm{O}\right)_{3}\right] \mathrm{X} \quad(\mathrm{X}=$ anion, $\mathrm{R}=$ alkyl or aryl), ${ }^{9-14}$ all of which display antiferromagnetic exchange interactions between the metal ions. ${ }^{9-15}$ The stability of this structural unit saw it widely employed thereafter as a starting material for the synthesis of a range of novel complexes, such as $\left[\mathrm{Cr}_{4} \mathrm{O}_{4}\right]^{8+}$ butterflies, ${ }^{16}$ an unusual tetrahedral $\left[\mathrm{Cr}_{4} \mathrm{~S}\right]^{10+}$ cage which displays ferromagnetic interactions resulting in the stabilisation of an $S=6$ ground state, ${ }^{17}$ and an extensive family of $\mathrm{Cr}_{6}, \mathrm{Cr}_{8}$ and $\mathrm{Cr}_{10}$ wheels. ${ }^{18-24}$ These rings are bridged by a combination of carboxylate ligands and $\mathrm{F}^{-}$or $\mathrm{OH}^{-}$ions, leading, in the main, to complexes with $S=0$ ground states; the exception being the complex $\left[\mathrm{Cr}_{10}(\mathrm{OMe})_{20}\left(\mathrm{O}_{2} \mathrm{CMe}\right)_{10}\right]$ which shows weak ferromagnetic exchange and an $S=$ 15 ground state. ${ }^{20}$ A number of other $\left[\mathrm{Cr}_{8}\right]$ and $\left[\mathrm{Cr}_{12}\right]$ clusters with different topologies have also been reported: these include a $\left[\mathrm{Cr}_{12} \mathrm{O}_{9}\right]^{18+}$ centred, pentacapped trigonal prism, a $\left[\mathrm{Cr}_{8} \mathrm{O}_{4}\right]^{16+}$ capped cubane, and a $\left[\mathrm{Cr}_{12} \mathrm{O}_{8}\right]^{20+}$ capped tricubane. ${ }^{13,18,25,26}$ Two additional octanuclear $\left\{\mathrm{Cr}_{8} \mathrm{O}_{2}\right\}^{20+}$ complexes with structures derived from fused octahedra are notable due to the lack of carboxylates, employing instead the 
tripodal alcohol ligands $\mathrm{H}_{3}$ thme and $\mathrm{H}_{4}$ peol. ${ }^{27}$ The largest homometallic $\mathrm{Cr}(\mathrm{III})$ complex reported to date, $\left[\mathrm{Cr}_{14}(\mathrm{bta})_{6} \mathrm{O}_{6}(\mathrm{OMe})_{18} \mathrm{Cl}_{6}\right]$ (btaH $=$ benzotriazole), whose metallic skeleton describes a hexacapped hexagonal bipyramid also contains no carboxylates. ${ }^{28}$ These latter two species hint that structurally novel clusters may be obtained by employing different ligand sets than those traditionally used.

In contrast, dinuclear chromium complexes are plentiful and have been widely studied, with monohydroxo-, dihydroxo(often referred to as "diols"), and oxo-bridged systems being particularly well documented. ${ }^{29-41}$ Magneto-structural correlations for the "diols" revealed that the key structural parameters dominating the magnetic exchange interaction are the Cr-O-Cr bridging angle $(\phi)$, the $\mathrm{Cr}-\mathrm{O}$ bond length $(r)$, and the dihedral angle between the bridging $\mathrm{Cr}_{2} \mathrm{O}_{2}$ plane and the $\mathrm{OH}$ vector of the bridging group $(\theta)$ (Fig. 1). ${ }^{42}$ The magnetic exchange in the majority of these dimers is antiferromagnetic in nature, with ferromagnetic exchange being found only in a small window of $\theta$ and $\phi$ values. $^{43}$ For H-bonded dimers it has been shown that both the $\mathrm{O} \cdots \mathrm{H} \cdots \mathrm{O}$ distance $(d)$ and the $\mathrm{Cr}-\mathrm{O} \cdots \mathrm{O}-\mathrm{Cr}$ torsion angle $(a)$ influence magnetic exchange. ${ }^{44,45}$

In order to extend these studies from di-hydroxo to dialkoxo bridged chromium dimers, and to investigate if the same magneto-structural correlation persists, we have made a family of $\left[\mathrm{Cr}_{2}^{\mathrm{III}}(\mathrm{OR})_{2}\right]$ complexes with the pyridine alcohol ligands 2-pyridinemethanol (hmpH), 2-pyridineethanol (hepH)

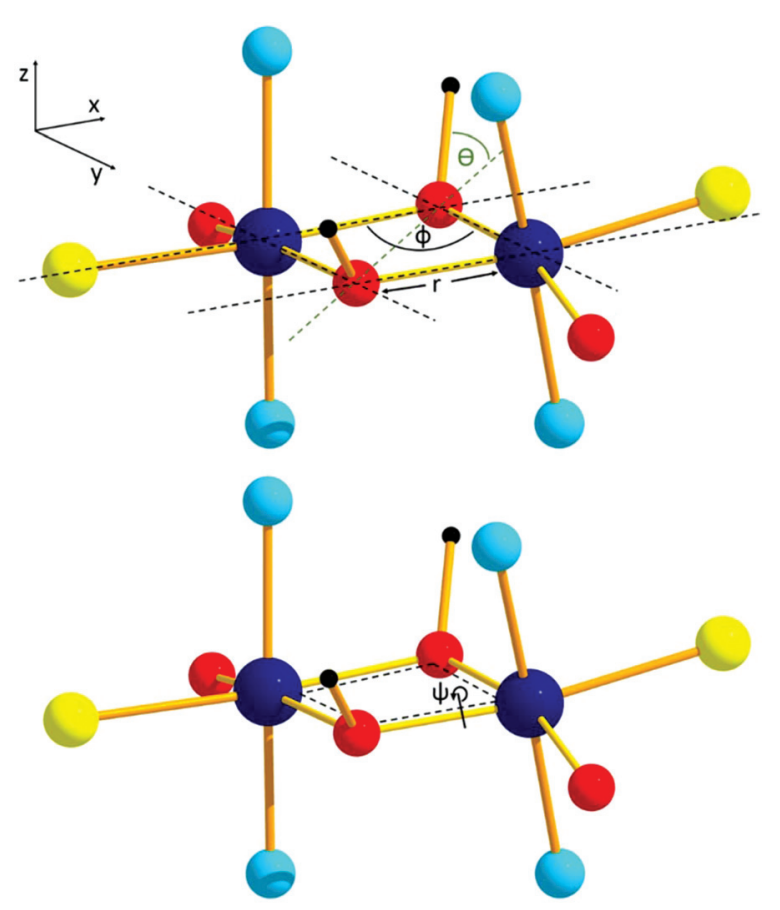

Fig. 1 Diagrammatic representation of the key structural parameters influencing the sign and magnitude of magnetic exchange in $\left[\mathrm{Cr}_{2}^{\mathrm{II \prime}}(\mathrm{OH})_{2}\right]$ dimers (top) and of another parameter, $\psi$, the $\mathrm{Cr}-\mathrm{O}-\mathrm{Cr}-\mathrm{O}$ dihedral angle, used in this study (bottom). Colour code: $\mathrm{Cr}=$ dark blue, $\mathrm{O}=$ red, $\mathrm{C} / \mathrm{H}=$ black. The light blue and yellow spheres represent generic donor atoms.

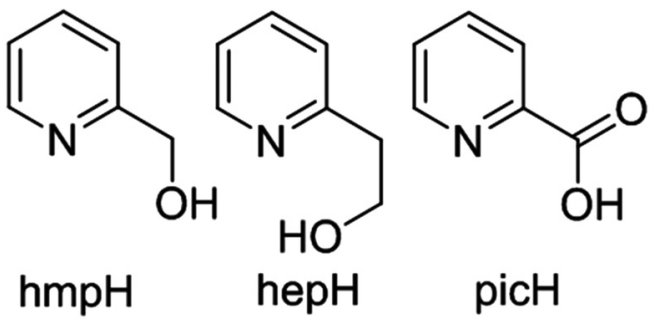

Fig. 2 Molecular structures of the pro-ligands (left to right) $\mathrm{hmpH}$, hepH and $\mathrm{picH}$.

and the oxidised version of hmpH, 2-picolinic acid (picH) (Fig. 2). These compounds have been structurally characterised using single crystal X-ray crystallography and their magnetic behaviour investigated through a combination of magnetometry and theoretical analysis.

\section{Experimental}

\section{Materials and physical measurements}

All chemicals were procured from commercial suppliers and used as received (reagent grade). Elemental analyses for $\mathrm{C}, \mathrm{H}$, $\mathrm{N}$ and $\mathrm{Cr}$ on all compounds were performed by Medac Ltd.

\section{Synthesis of $\left[\mathrm{Cr}_{2}(\mathrm{MeO})_{2}(\text { pic })_{4}\right] \cdot \frac{1}{2} \mathrm{MeOH} \cdot \frac{1}{2} \mathrm{Et}_{2} \mathrm{O}$ (1)}

Method 1: $\mathrm{Cr}\left(\mathrm{NO}_{3}\right)_{3} \cdot 9 \mathrm{H}_{2} \mathrm{O}(0.800 \mathrm{~g}, 2 \mathrm{mmol})$ was dissolved with hmpH $(0.190 \mathrm{ml}, 2 \mathrm{mmol}), \mathrm{NEt}_{3}(0.279 \mathrm{ml}, 2 \mathrm{mmol})$ and $\mathrm{NaO}_{2} \mathrm{CPh}(0.288 \mathrm{~g}, 2 \mathrm{mmol})$ in $\mathrm{MeOH}(25 \mathrm{ml})$. The reaction was left overnight with continuous stirring. $10 \mathrm{ml}$ samples of the resulting dark blue solution were heated in Teflon-lined autoclaves at $140{ }^{\circ} \mathrm{C}$ for 24 hours. The solution was filtered and vapour diffused with diethyl ether. Pink block-shaped crystals were formed after 2 weeks, which were suitable for x-ray diffraction. Yield $7.1 \mathrm{mg}$ (2.01\% by hmpH weight). Anal. calcd (\%) for $\mathrm{C}_{26} \mathrm{H}_{22} \mathrm{Cr}_{2} \mathrm{~N}_{4} \mathrm{O}_{10}$ : C 47.72, $\mathrm{H}$ 3.39, Cr 15.89, N 8.56; found: C 47.97 H 3.93, Cr 15.30, N 8.04.

Method 2: $\mathrm{Cr}\left(\mathrm{NO}_{3}\right)_{3} \cdot 9 \mathrm{H}_{2} \mathrm{O}(0.800 \mathrm{~g}, 2 \mathrm{mmol})$ was dissolved with picH $(0.492 \mathrm{~g}, 4 \mathrm{mmol})$ in $\mathrm{MeOH}(20 \mathrm{ml}) . \mathrm{NEt}_{3}(0.558 \mathrm{ml}$, $4 \mathrm{mmol}$ ) was then added dropwise and the reaction was left overnight with continuous stirring. $10 \mathrm{ml}$ samples of the resulting dark blue solution were heated in Teflon-lined autoclaves at $140{ }^{\circ} \mathrm{C}$ for 24 hours. Slow cooling to room temperature yielded thin purple plate crystals which were suitable for $\mathrm{X}$-ray diffraction. Yield $215.8 \mathrm{mg}(30.50 \%$ by chromium weight). Anal. calcd (\%) for $\mathrm{C}_{26} \mathrm{H}_{22} \mathrm{Cr}_{2} \mathrm{~N}_{4} \mathrm{O}_{10}$ : C 47.72, H 3.39, Cr 15.89, N 8.56; found: C 47.82 H 3.77, Cr 15.75, N 8.98.

\section{Synthesis of $\left[\mathrm{Cr}_{2}(\mathrm{hmp})_{2}(\mathrm{pic})_{2} \mathrm{Cl}_{2}\right](2)$}

Method 1: $\mathrm{CrCl}_{3} \cdot 6 \mathrm{H}_{2} \mathrm{O}(0.533 \mathrm{~g}, 2 \mathrm{mmol})$ was dissolved with $\mathrm{hmpH}(0.380 \mathrm{ml}, 4 \mathrm{mmol})$ in $\mathrm{MeCN}(25 \mathrm{ml})$ with continuous stirring. NaOMe $(0.216 \mathrm{~g}, 4 \mathrm{mmol})$ was then added to the solution and the reaction was left to stir overnight at room temperature. The mixture was then heated for 1.5 hours at $60{ }^{\circ} \mathrm{C}$, affording a dark green solution. $10 \mathrm{ml}$ samples of the resulting 
solution were heated in Teflon-lined autoclaves at $120^{\circ} \mathrm{C}$ for 12 hours. Slow cooling to room temperature yielded brown block-shaped crystals, which were suitable for X-ray diffraction. Yield $101.8 \mathrm{mg}$ (16.02\% by chromium weight). Anal. calcd (\%) for $\mathrm{C}_{24} \mathrm{H}_{20} \mathrm{Cl}_{2} \mathrm{Cr}_{2} \mathrm{~N}_{4} \mathrm{O}_{6}$ : C 45.37, $\mathrm{H}$ 3.17, $\mathrm{Cr}$ 16.37, $\mathrm{N}$ 8.82; found: C 45.03, H 3.29, Cr 15.83, N 8.52.

Method 2: $\mathrm{CrCl}_{3} \cdot 6 \mathrm{H}_{2} \mathrm{O}(0.533 \mathrm{~g}, 2 \mathrm{mmol})$ was dissolved with hmpH $(0.190 \mathrm{ml}, 2 \mathrm{mmol})$ and picH $(0.246 \mathrm{~g}, 2 \mathrm{mmol})$ in MeCN (20 ml) with continuous stirring. NaOMe $(0.216 \mathrm{~g}$, $4 \mathrm{mmol}$ ) was then added to the solution and the reaction was left to stir overnight at room temperature. $10 \mathrm{ml}$ samples of the resulting dark green solution were heated in Teflonlined autoclaves at $120{ }^{\circ} \mathrm{C}$ for 12 hours. Slow cooling to room temperature yielded brown rod-shaped crystals, which were suitable for X-ray diffraction. Yield $532.6 \mathrm{mg}(83.83 \%$ by chromium weight). Anal. calcd (\%) for $\mathrm{C}_{24} \mathrm{H}_{20} \mathrm{Cl}_{2} \mathrm{Cr}_{2} \mathrm{~N}_{4} \mathrm{O}_{6}$ : $\mathrm{C} 45.37, \mathrm{H} \mathrm{3.17}, \mathrm{Cr} 16.37, \mathrm{~N} 8.82$; found: C 45.84, $\mathrm{H} 3.50$, Cr 15.89, N 8.50.

\section{Synthesis of $\left[\mathrm{Cr}_{2}(\mathrm{hmp})_{2}(\mathrm{pic})_{2} \mathrm{Br}_{2}\right]$ (3)}

Method 1: $\mathrm{CrBr}_{3} \cdot 6 \mathrm{H}_{2} \mathrm{O}(0.800 \mathrm{~g}, 2 \mathrm{mmol})$ was dissolved with hmpH $(0.380 \mathrm{ml}, 4 \mathrm{mmol})$ in $\mathrm{MeCN}$ (25 ml) with continuous stirring. NaOMe $(0.216 \mathrm{~g}, 4 \mathrm{mmol})$ was then added to the solution and the reaction was left to stir overnight at room temperature. The mixture was then heated for 1.5 hours at $60{ }^{\circ} \mathrm{C}$, giving a dark green solution. $10 \mathrm{ml}$ samples of this solution were heated in Teflon-lined autoclaves at $120{ }^{\circ} \mathrm{C}$ for 12 hours. Slow cooling to room temperature yielded purple prismshaped and purple rod-shaped crystals, which were suitable for X-ray diffraction studies. Both crystal types were of the same structure. Yield $169.3 \mathrm{mg}$ (23.38\% by chromium weight). Anal. calcd (\%) for $\mathrm{C}_{24} \mathrm{H}_{20} \mathrm{Br}_{2} \mathrm{Cr}_{2} \mathrm{~N}_{4} \mathrm{O}_{6}$ : C 39.80, $\mathrm{H}$ 2.78, Cr 14.36, N 7.74; found: C 40.09, H 2.63, Cr 14.06, N 7.45.

Method 2: $\mathrm{CrBr}_{3} \cdot 6 \mathrm{H}_{2} \mathrm{O}(0.800 \mathrm{~g}, 2 \mathrm{mmol})$ was dissolved with hmpH $(0.190 \mathrm{ml}, 2 \mathrm{mmol})$ and picH (0.246 g, $2 \mathrm{mmol})$ in MeCN (20 ml) with continuous stirring. NaOMe $(0.216 \mathrm{~g}$, $4 \mathrm{mmol}$ ) was then added to the solution and the reaction was left to stir overnight at room temperature. $10 \mathrm{ml}$ samples of the resulting dark green solution were heated in Teflon-lined autoclaves at $120{ }^{\circ} \mathrm{C}$ for 12 hours. Slow cooling to room temperature yielded purple rod-shaped crystals, which were suitable for X-ray diffraction studies. Yield $417.6 \mathrm{mg}$ (57.66\% by chromium weight). Anal. calcd (\%) for $\mathrm{C}_{24} \mathrm{H}_{20} \mathrm{Br}_{2} \mathrm{Cr}_{2} \mathrm{~N}_{4} \mathrm{O}_{6}$ : C 39.80, $\mathrm{H}$ 2.78, Cr 14.36, N 7.74; found: C 39.64, H 2.82, Cr 13.94, N 7.74 .

\section{Synthesis of $\left[\mathrm{Cr}_{2}(\mathrm{hmp})_{2} \mathrm{Cl}_{4}\left(\mathrm{H}_{2} \mathrm{O}\right)_{2}\right] \cdot 2 \mathrm{Et}_{2} \mathrm{O}(4)$}

$\mathrm{CrCl}_{3} \cdot 6 \mathrm{H}_{2} \mathrm{O}(0.533 \mathrm{~g}, 2 \mathrm{mmol})$ was dissolved with $\mathrm{hmpH}$ (0.190 ml, $2 \mathrm{mmol}$ ) in $\mathrm{MeCN}$ (25 ml) with continuous stirring. NaOMe $(0.108 \mathrm{~g}, 2 \mathrm{mmol})$ was then added to the solution and the reaction was left to stir overnight at room temperature. The mixture was then heated for 1.5 hours at $60{ }^{\circ} \mathrm{C}$ to produce a dark green solution. The solution was then filtered and diffused with diethyl ether. Green block-shaped crystals were formed after 1 week, which were suitable for X-ray diffraction. Yield $98.2 \mathrm{mg}$ (19.71\% by chromium weight). Anal. calcd (\%) for $\mathrm{C}_{12} \mathrm{H}_{16} \mathrm{Cl}_{4} \mathrm{Cr}_{2} \mathrm{~N}_{2} \mathrm{O}_{4}$ : C 28.94, $\mathrm{H}$ 3.24, Cr 20.88, N 5.62; found: C 29.08, H 3.22, Cr 20.81, N 5.55.

\section{Synthesis of $\left[\mathrm{Cr}_{2}(\mathrm{hmp})_{2} \mathrm{Cl}_{4}(\mathrm{pyr})_{2}\right] \cdot 2 \operatorname{pyr}(5)$}

Powdered $\left[\mathrm{Cr}_{2}(\mathrm{hmp})_{2} \mathrm{Cl}_{4}\left(\mathrm{H}_{2} \mathrm{O}\right)_{2}\right] \cdot 2 \mathrm{Et}_{2} \mathrm{O}(4)(14 \mathrm{mg}, 0.028 \mathrm{mmol})$ was dissolved in pyridine $(10 \mathrm{ml})$ with continuous stirring for $30 \mathrm{~min}$. The resulting green solution was filtered and a vapour diffusion was set up with diethyl ether. Dark green blockshaped crystals were formed after 2 days, which were suitable for X-ray diffraction studies. Yield $8.4 \mathrm{mg}(38.53 \%$ by chromium weight). Anal. calcd (\%) for $\mathrm{C}_{32} \mathrm{H}_{32} \mathrm{Cl}_{4} \mathrm{Cr}_{2} \mathrm{~N}_{6} \mathrm{O}_{2}$ : C 49.37, $\mathrm{H}$ 4.14, Cr 13.36, N 10.80; found: C 48.97, H 3.81, Cr 13.39, N 10.49 .

\section{Synthesis of $\left[\mathrm{Cr}_{2}(\mathrm{hmp})_{2} \mathrm{Cl}_{4}(4 \text {-picoline })_{2}\right](6)$}

Powdered $\quad\left[\mathrm{Cr}_{2}(\mathrm{hmp})_{2} \mathrm{Cl}_{4}\left(\mathrm{H}_{2} \mathrm{O}\right)_{2}\right] \cdot 2 \mathrm{Et}_{2} \mathrm{O} \quad$ (4) (16.6 mg, $0.033 \mathrm{mmol})$ was dissolved in 4-picoline $(10 \mathrm{ml})$ with continuous stirring for $30 \mathrm{~min}$. The resulting green solution was filtered and a vapour diffusion was set up with hexane. Blue block-shaped crystals were formed after 5 days, which were suitable for X-ray diffraction studies. Yield $5.3 \mathrm{mg}(24.77 \%$ by chromium weight). Anal. calcd (\%) for $\mathrm{C}_{24} \mathrm{H}_{26} \mathrm{Cl}_{4} \mathrm{Cr}_{2} \mathrm{~N}_{4} \mathrm{O}_{2}$ : $\mathrm{C} 44.46, \mathrm{H}$ 4.04, $\mathrm{Cr}$ 16.04, N 8.64; found: C 43.99, $\mathrm{H} 4.02$, Cr 15.89, N 8.41.

\section{Synthesis of $\left[\mathrm{Cr}_{2}(\text { hep })_{2} \mathrm{Cl}_{4}\left(\mathrm{H}_{2} \mathrm{O}\right)_{2}\right] \cdot 2 \mathrm{MeCN}(7)$}

$\mathrm{CrCl}_{3} \cdot 6 \mathrm{H}_{2} \mathrm{O}(0.533 \mathrm{~g}, 2 \mathrm{mmol})$ was dissolved with hepH $(0.383 \mathrm{ml}, 3 \mathrm{mmol})$ in $\mathrm{MeCN}$ ( $25 \mathrm{ml}$ ) with continuous stirring. $\mathrm{NaBF}_{4}(0.329 \mathrm{~g}, 3 \mathrm{mmol})$ was then added to the solution and the reaction mixture left to stir for 4 hours at room temperature. The resulting cloudy green/grey solution was filtered and diffused with hexane. Brown block-shaped crystals were formed after 2 weeks, which were suitable for X-ray diffraction. Yield $52.2 \mathrm{mg}$ (9.92\% by chromium weight). Anal. calcd (\%) for $\mathrm{C}_{14} \mathrm{H}_{20} \mathrm{Cl}_{4} \mathrm{Cr}_{2} \mathrm{~N}_{2} \mathrm{O}_{4}$ : C 31.96, $\mathrm{H}$ 3.83, Cr 19.77, N 5.32; found: C 32.04, H 3.73, Cr 20.09, N 5.77.

\section{Synthesis of $\left[\mathrm{Cr}(\mathrm{hmp})(\mathrm{hmpH}) \mathrm{Cl}_{2}\right] \cdot \mathrm{MeCN}(8)$}

A solution of hmpH $(0.285 \mathrm{ml}, 3 \mathrm{mmol})$ and $\mathrm{NEt}_{3}(0.420 \mathrm{ml}$, $3 \mathrm{mmol}$ ) dissolved in MeCN (25 ml) was continuously stirred for 10 minutes. $\mathrm{CrCl}_{3} \cdot 6 \mathrm{H}_{2} \mathrm{O}(0.533 \mathrm{~g}, 2 \mathrm{mmol})$ was then added and the reaction was left to stir for 2.5 hours at room temperature. The resulting cloudy brown solution was filtered and vapour diffused with diethyl ether. Dark green block-shaped crystals were formed after 3 days, which were suitable for X-ray diffraction. Yield $4.7 \mathrm{mg}$ ( $0.92 \%$ by hmpH weight). Anal. calcd (\%) for $\mathrm{C}_{12} \mathrm{H}_{13} \mathrm{Cl}_{2} \mathrm{CrN}_{2} \mathrm{O}_{2}$ : C 42.37, $\mathrm{H} \mathrm{3.85,} \mathrm{Cr} \mathrm{15.29,} \mathrm{N} \mathrm{8.24;}$ found: C 42.03, H 4.10, Cr 15.04, N 8.35.

\section{X-ray crystallography}

Diffraction data for samples 1-8 were collected using a Rigaku Oxford Diffraction SuperNova diffractometer with $\mathrm{MoK}_{\alpha}$ $(\mathbf{1 - 4}, \mathbf{8})$ and $\mathrm{CuK}_{\alpha}(\mathbf{5}, \mathbf{6}, \mathbf{7})$ radiation, and are given in Tables S1 and S2 in the ESI. $\dagger$ An Oxford Cryosystems Cryostream 700+ low temperature device was used to maintain a crystal temperature of $120 \mathrm{~K}$. The structures were solved using ShelXT 
or ShelXS by direct $(\mathbf{1 - 3}, \mathbf{5}, \mathbf{6}, \mathbf{8})$ or Patterson methods $(\mathbf{4}, 7)$ and refined with version $2014 / 6$ of ShelXL interfaced with Olex2. ${ }^{46,47}$ All non-hydrogen atoms were refined using anisotropic displacement parameters. In structures $\mathbf{1}$ and 3-8 $\mathrm{O} / \mathrm{N}$-bound $\mathrm{H}$ atoms were initially identified from a difference Fourier map and refined with geometric restraints as appropriate. C-bound $\mathrm{H}$ atoms were placed in calculated positions geometrically and refined using the riding model. In structure 2 all $\mathrm{H}$ atoms were identified from a difference map and refined freely. CCDC: 1482832-1482837 and 1540438-1540439.

\section{Magnetic data collection}

Magnetic susceptibility measurements in the temperature range $T=2-300 \mathrm{~K}$ were performed on a Quantum Design MPMS XL SQUID magnetometer equipped with a $7 \mathrm{~T}$ dc magnet on finely ground samples of 1-8. The observed paramagnetic susceptibilities were corrected for diamagnetic contributions using Pascal's constants. The measurements were performed under magnetic fields of $0.1 \mathrm{~T}(2-5,7), 0.5 \mathrm{~T}(6,8)$ and $1 \mathrm{~T}(\mathbf{1})$.

\section{Computational details}

All calculations were carried out with the Gaussian09 program package using the UB3LYP functional with TZV basis sets. ${ }^{48-51}$ Although additional polarisation functions could be employed, it was found that TZV alone yielded good numerical accuracy, as seen in previous studies. ${ }^{52}$ The broken-symmetry approach has been employed to describe the unrestricted solutions of the high spin (E-HS) and low spin (E-BS) states, and the corresponding $J$ values were computed from the difference between E-HS and E-BS. ${ }^{53}$ A quadratic convergence method was employed to determine the more stable wave functions in the SCF process. We have previously established a computational approach for reliably computing exchange coupling constants in dinuclear complexes using broken-symmetry DFT and this methodology has been employed here. ${ }^{54-56}$

\section{Results and discussion}

\section{Syntheses}

Both hmpH and hepH (Fig. 2) have found widespread use in the coordination chemistry of an array of $3 \mathrm{~d}$ metals, including $\mathrm{Mn},{ }^{57,58} \mathrm{Fe},{ }^{59} \mathrm{Ni},{ }^{60} \mathrm{Co},{ }^{61} \mathrm{Cu},{ }^{62} \mathrm{Ti}^{63}{ }^{63} \mathrm{Zn},{ }^{64}$ and $\mathrm{V},{ }^{65}$ but as yet nothing has been reported with $\mathrm{Cr}$ (III). Our primary interest was therefore to examine simple reactions between pyridine alcohol ligands and $\mathrm{Cr}$ (III) salts in the absence of any other chelating or bridging ligands. In order to do this, reactions were carried out using a general reaction scheme whereby the metal salt, ligand and base were combined in either MeCN or $\mathrm{MeOH}$. Given the kinetic inertness of the $\mathrm{Cr}$ (III) ion we began by examining solvothermal methods, initially at $T=140{ }^{\circ} \mathrm{C}$. However, under these conditions the hmpH ligand is oxidised to picolinic acid, affording compound $\mathbf{1}$. We presume this is also the reason, or at least one contributory factor, for the very small yield of $\mathbf{1}$, and repetition of the reaction with picolinic

acid in place of hmpH produces $\mathbf{1}$ in much higher yield. In addition the yields of complexes 2 and 3, in which partial oxidation of the ligand occurs, are greatly increased by the equivalent reactions with picolinic acid. This partial oxidation was achieved by reducing the temperature to $T=120{ }^{\circ} \mathrm{C}$. Upon further reduction of the temperature ( $T=100 \mathrm{~K}$ and below) no ligand oxidation took place and complexes 4-8 were formed. This was also the case for reactions carried out on the bench at $T<60{ }^{\circ} \mathrm{C}$. It is interesting to note that both compounds 7 and $\mathbf{8}$ were synthesised under ambient conditions, and for compound $\mathbf{8}$ the order of addition also appears crucial, since no crystalline material was obtained in alternative reactions in which the same ingredients were added in different sequences to that described in the Experimental section.

\section{Structure description}

The molecular structures of the five different structure types (1, 2, 5, 7 \& 8) are presented in Fig. 3, with the important metric parameters listed in Tables 1 and 2. The structures of compounds 3, 4 and 6 are entirely analogous to that of compounds 2, 7 and 5, respectively. Complex 1 (Fig. 3A) crystallises in the monoclinic space group $P 2_{1} / n$ with the whole cluster in the asymmetric unit (ASU). The Cr centres are bridged by two $\mu_{2}$-OMe groups $\left(\mathrm{Cr} 1-\mathrm{O}-\mathrm{Cr} 2=100.61^{\circ}, 101.76^{\circ}\right)$, with the dis-

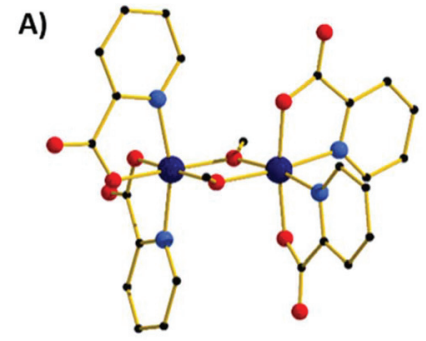

C)
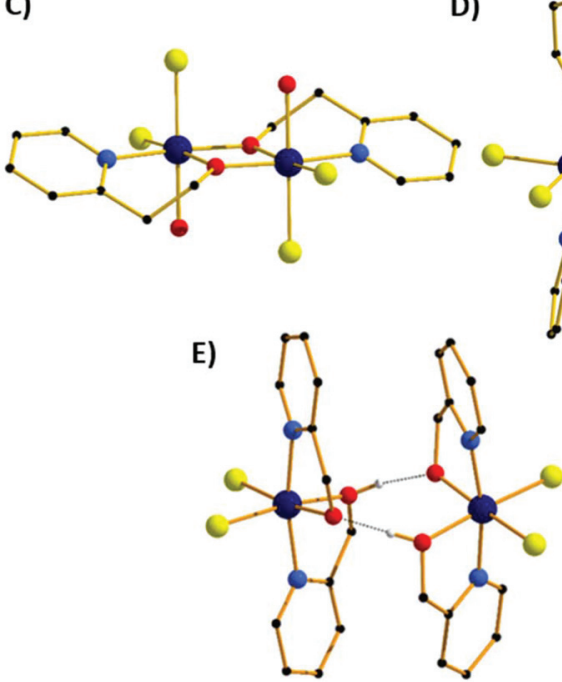

Fig. 3 Molecular structures of compounds 1 (A), 2 (B), 7 (C), 5 (D) and 8 (E). Colour code: $\mathrm{Cr}=$ dark blue, $\mathrm{O}=$ red, $\mathrm{N}=$ light blue, $\mathrm{C}=$ black, $\mathrm{Cl}=$ yellow. $\mathrm{H}$-atoms and solvent molecules of crystallisation omitted for clarity. The dashed lines in (E) represent $\mathrm{H}$-bonds. 
Table 1 Pertinent structural parameters for the di-alkoxo bridged compounds 1-7. $r=\mathrm{Cr}-\mathrm{O}$ bond length, $\Phi=\mathrm{Cr}-\mathrm{O}-\mathrm{Cr}$ bridging angle, $\theta=\mathrm{di}-$ hedral angle between the bridging $\mathrm{Cr}_{2} \mathrm{O}_{2}$ plane and the OR vector of the bridging group, $\psi=\mathrm{Cr}-\mathrm{O}-\mathrm{Cr}-\mathrm{O}$ dihedral angle

\begin{tabular}{llllll}
\hline & $\mathrm{Cr}-\mathrm{Cr}[\AA]$ & $r[\AA]$ & $\Phi\left[^{\circ}\right]$ & $\theta\left[^{\circ}\right]$ & $\psi\left[^{\circ}\right]$ \\
\hline $\mathbf{1}$ & 3.029 & $1.951-1.970$ & $100.67,101.76$ & $21.13,3.45$ & 0.91 \\
$\mathbf{2}$ & 3.058 & $1.979-1.982$ & 101.11 & 45.27 & 2.43 \\
$\mathbf{3}$ & 3.050 & $1.975-1.980$ & 100.91 & 45.71 & 3.21 \\
$\mathbf{4}$ & 3.029 & $1.943-1.969$ & 101.50 & 23.78 & 0.00 \\
& 3.039 & $1.958-1.964$ & 101.61 & 17.70 & 0.00 \\
$\mathbf{5}$ & 3.035 & $1.967-1.977$ & 100.63 & 55.44 & 1.55 \\
& 3.059 & $1.974-2.000$ & 100.65 & 48.84 & 4.90 \\
$\mathbf{6}$ & 3.091 & $1.987-1.992$ & 101.99 & 46.06 & 1.89 \\
& 3.099 & $1.980-2.005$ & 102.10 & 46.25 & 0.44 \\
7 & 3.057 & $1.943-1.963$ & 102.99 & 7.00 & 0.00 \\
& & & & & \\
\hline
\end{tabular}

Table 2 Important structural parameters for the $\mathrm{H}$-bridged dimer $8 . r=$ $\mathrm{Cr}-\mathrm{O}$ bond length, $d=\mathrm{O} \cdots \mathrm{H} \cdots \mathrm{O}$ distance, $\mathrm{a}=\mathrm{Cr}-\mathrm{O} \cdots \mathrm{O}-\mathrm{Cr}$ torsion angle

\begin{tabular}{lllll}
\hline & $\mathrm{Cr}-\mathrm{Cr}[\AA]$ & $r[\AA]$ & $d[\AA]$ & $a\left[{ }^{\circ}\right]$ \\
\hline 8 & 5.093 & 1.965 & 2.399 & 58.18
\end{tabular}

torted octahedral coordination sphere on each metal centre completed by two $\mathrm{N}$-atoms and two O-atoms from two bidentate picolinate anions, which lie perpendicular to each other. In the extended structure the cluster and solvent of crystallisation form alternating zig-zag chains along the $a$-axis of the cell (Fig. S1 $\dagger$ ), with $\mathrm{H}$-bonds between the solvent and the picolinate ligands forming layers. Between these sheets exist intermolecular $\pi-\pi$ interactions between the pyridine rings of the picolinate ligands $(\mathrm{C} \cdots \mathrm{C}, \sim 3.6 \AA)$.

The second structural type is seen in compounds 2 and 3 (Fig. 3B shows compound 2). Both complexes crystallise in the orthorhombic space group Pnn2 with half the molecule in the ASU. The metal centres are bridged by two $\mu_{2}$-OR groups belonging to the $\mathrm{hmp}^{-}$ligands, with $\mathrm{Cr}-\mathrm{O}-\mathrm{Cr}$ angles of $101.11^{\circ}(2)$ and $100.91^{\circ}(3)$. The distorted octahedral coordination sphere at each $\mathrm{Cr}(\mathrm{III})$ ion is completed by the $\mathrm{N}$-atom from the bridging $\mathrm{hmp}^{-}$, a chelating picolinate ligand and a chloride ion. The $\mathrm{pic}^{-}$ions sit above, and the $\mathrm{hmp}^{-}$ions below the $\left[\mathrm{Cr}_{2} \mathrm{O}_{2}\right]$ plane (as drawn in Fig. 3B), resulting in the methylene $\mathrm{C}$-atoms of the $\mathrm{hmp}^{-}$ligands also being significantly below this plane. The aromatic rings of the same ligand type sit in a near parallel fashion with respect to each other at C...C distances of $\sim 3.3 \AA$. In the crystal the dimers pack in a headto-tail fashion forming columnar arrays down the $c$-axis of the cell (Fig. S2 $\dagger$ ). There are numerous short contacts between the picolinate O-atoms/terminal chlorides on one molecule and aromatic $\mathrm{H}$-atoms on neighbouring molecules throughout the extended structure.

Compounds 4 and 7 (Fig. 3C shows compound 7) crystallise in the triclinic space group $P \overline{1}$. Crystals of $\mathbf{4}$ contain two crystallographically distinct dimers, 7 just one. In each case the $\mathrm{Cr}(\mathrm{III})$ ions are bridged by two $\mu_{2}$-OR O-atoms belonging to the pyridine alcohol ligands $\left(\mathrm{hmp}^{-}, \mathbf{4}\right.$; hep $\left.{ }^{-}, 7\right)$ with $\mathrm{Cr}-\mathrm{O}-\mathrm{Cr}$ angles of $101.61^{\circ} / 101.50$ (4) and $102.99^{\circ}$ (7). The remaining coordination sites of the octahedral $\mathrm{Cr}(\mathrm{III})$ ion contain a water molecule, two cis chloride ions and the $\mathrm{N}$-atom from the pyridine alcohol. In contrast to complexes $\mathbf{1}$ and $\mathbf{2}$ (and 8), the pyridine alcohol ligands lie approximately in the same plane as the $\left[\mathrm{Cr}_{2} \mathrm{O}_{2}\right]$ moiety; the extra methylene group in the hep ${ }^{-}$ ligand in 7 causing the aromatic rings to be tilted out of the plane somewhat. In 4 the terminal water molecules are $\mathrm{H}$-bonded to diethyl ether molecules of crystallisation $(\mathrm{O} \cdots \mathrm{O}$, $2.697 \AA, 2.766 \AA)$ which sit above/below the aromatic rings (Fig. S3†), creating layers of solvent molecules between layers of dimers. Within these layers the closest intermolecular interactions involve $\pi-\pi(\mathrm{C} \cdots \mathrm{C}, \sim 3.5 \AA)$ and $\mathrm{Cl} \cdots \mathrm{C}(\mathrm{Ar})(\sim 3.7 \AA)$ interactions. In 7 the terminally bonded water molecules are $\mathrm{H}$-bonded to MeCN molecules of crystallisation in a manner akin to that of $\mathbf{4}$, again creating a layered structure with $\pi-\pi(\mathrm{C} \cdots \mathrm{C}, \sim 3.6 \AA)$ and $\mathrm{Cl} \cdots \mathrm{C}(\mathrm{Ar})(\sim 3.5 \AA)$ interactions between neighbouring molecules (Fig. S6†).

Substitution of the water molecules in $\mathbf{4}$ with pyridine to give complex 5 , or 4 -methylpyridine to give $\mathbf{6}$, leads to dramatic structural changes. The result is that the $\mathrm{hmp}^{-}$ligands twist out of the plane to face each other, and the pyridines sit above the plane parallel to each other. Complex $\mathbf{5}$ crystallises in the tetragonal space group $I 4_{1}, 6$ in the monoclinic space group $P 2 / c$ and both have two molecules in the ASU. The $\mathrm{Cr}$ ions are bridged by two $\mu_{2}$-OR groups belonging to the $\mathrm{hmp}^{-}$ligands, with $\mathrm{Cr}-\mathrm{O}-\mathrm{Cr}$ angles of $100-102^{\circ}$. The remaining coordination sites of the distorted octahedral $\mathrm{Cr}(\mathrm{III})$ ion contain a pyridine molecule, two cis chloride ions and the $\mathrm{N}$-atom from the pyridine alcohol. The pyridine molecules sit above, and the $\mathrm{hmp}^{-}$ ions below the $\left[\mathrm{Cr}_{2} \mathrm{O}_{2}\right]$ plane (as drawn in Fig. 3D), resulting in the methylene $\mathrm{C}$-atoms of the $\mathrm{hmp}^{-}$ligands also being significantly below this plane. The aromatic rings of the same ligand type sit in a near parallel fashion with respect to each other at C...C distances of $\sim 3.2-3.4 \AA$. In the crystal of 5 , the dimers pack in columnar arrays down the $c$-axis of the cell, each rotated $90^{\circ}$ in the $c$-axis with respect to the next. This arrangement leaves channels down the $c$-axis which are occupied by pyridine molecules of crystallisation (Fig. S4 †). In 6 there is no solvent of crystallisation present. Columns of identically oriented molecules are seen down the $b$-axis with rows of columns in $c$ which rotate the molecule $45^{\circ}$ between two repeating rows (Fig. S5 $\dagger$ ).

Compound 8 crystallises in the tetragonal space group $\mathrm{P4}_{2} / n b c$, and describes an H-bonded dimer of [ $\left.\mathrm{Cr}(\mathrm{hmp})(\mathrm{hmpH}) \mathrm{Cl}_{2}\right]$ moieties (Fig. 3E). Each monomer contains two bidentate hmp ${ }^{-}$ ligands situated such that their $\mathrm{N}$-atoms are trans to one another, and two cis $\mathrm{Cl}^{-}$ions. The monomers sit face-to-face with their nearest neighbours, linked by two $\mathrm{H}$-bonds between the O-atoms of the hmpH/hmp ${ }^{-}$ligands $(\mathrm{O} \cdots \mathrm{H} \cdots \mathrm{O}, 2.399 \AA)$ with one proton being shared between the two $\mathrm{O}$-atoms. The two monomers are slightly twisted with respect to one another $\left(\mathrm{Cl}-\mathrm{Cr} \cdots \mathrm{Cr}-\mathrm{Cl}, \sim 10.6^{\circ}\right)$, with the aromatic rings above and below the " $\left[\mathrm{Cr}_{2} \mathrm{O}_{2}\right]$ " plane aligned in a parallel fashion $(\mathrm{C} \cdots \mathrm{C},>3.5 \AA$ ̊).

In the extended structure (Fig. 4) the dimers pack in a columnar fashion down the $c$-axis of the cell, with one dimer 


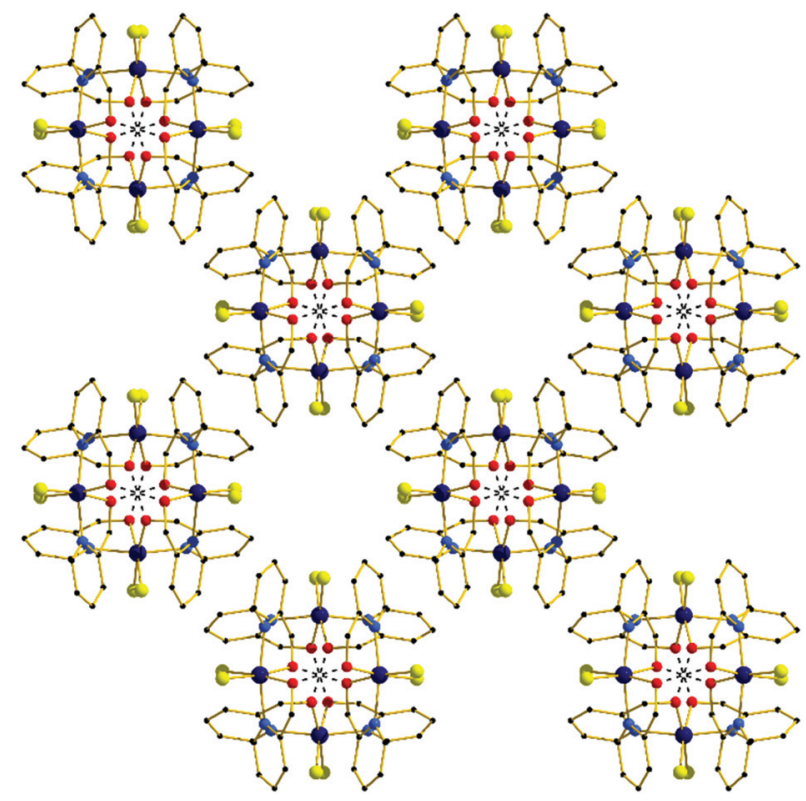

Fig. 4 The extended structure in complex 8 viewed down the c-axis, highlighting the square tile like architecture. H-bonds are shown as dashed lines.

rotated $90^{\circ}$ with respect to its neighbour, creating an aesthetically pleasing square tile type of architecture, with tubular pores accounting for approximately $9 \%$ of the unit cell volume. The closest intermolecular interactions occur between neighbouring aromatic rings $(\pi-\pi, \sim 3.4 \AA)$.

\section{SQUID magnetometry}

DC magnetic susceptibility measurements were carried out on powdered polycrystalline samples of compounds 1-8 in applied magnetic fields of $0.1 \mathrm{~T}(\mathbf{2}-5,7), 0.5 \mathrm{~T}(\mathbf{6}, \mathbf{8})$ and $1 \mathrm{~T}(\mathbf{1})$ over the temperature range $T=2-300 \mathrm{~K}$. The experimental results are plotted in Fig. 5 as the $\chi_{\mathrm{M}} T$ product versus $T$, where $\chi_{\mathrm{M}}$ is the molar magnetic susceptibility.

At $300 \mathrm{~K}$ the $\chi_{\mathrm{M}} T$ values of approximately 3.31 (1), 3.20 (2), 3.54 (3), 3.06 (4), 3.49 (5), 3.36 (6) 2.94 (7) and $3.63(8) \mathrm{cm}^{3} \mathrm{~K} \mathrm{~mol}^{-1}$ are somewhat lower than that expected for two $s=3 / 2$ non-interacting ions with $g=2.00\left(3.75 \mathrm{~cm}^{3} \mathrm{~K} \mathrm{~mol}^{-1}\right)$. For all eight compounds the value of $\chi_{\mathrm{M}} T$ decreases gradually with decreasing temperature to reach $T=2 \mathrm{~K}$ values of $0.04(\mathbf{1}), 0.14$ (2), 0.10 (3), 0.16 (4), 0.10 (5), 0.06 (6) 0.06 (7) and 0.59 (8) $\mathrm{cm}^{3} \mathrm{~K} \mathrm{~mol}^{-1}$. This indicates the presence of relatively weak antiferromagnetic interactions between the $\mathrm{Cr}$ (III) ions and the stabilisation of diamagnetic ground states in all eight cases (Fig. S7-14†).

$$
\hat{H}=\mu_{\mathrm{B}} B \sum_{i} g_{i} \hat{S}_{i}-2 \sum_{i . j<i} J_{i j} \hat{S}_{i} \hat{S}_{j}
$$

In order to fit the data, the isotropic spin-Hamiltonian (1) was employed, where the indices $i$ and $j$ refer to the two $\mathrm{Cr}(\mathrm{III})$ ions, $\mu_{\mathrm{B}}$ is the Bohr magneton, $B$ is the applied magnetic field, $g$ is the $g$-factor of the $\operatorname{Cr}(\mathrm{III})$ ions (2.00), $\hat{S}$ is a spin

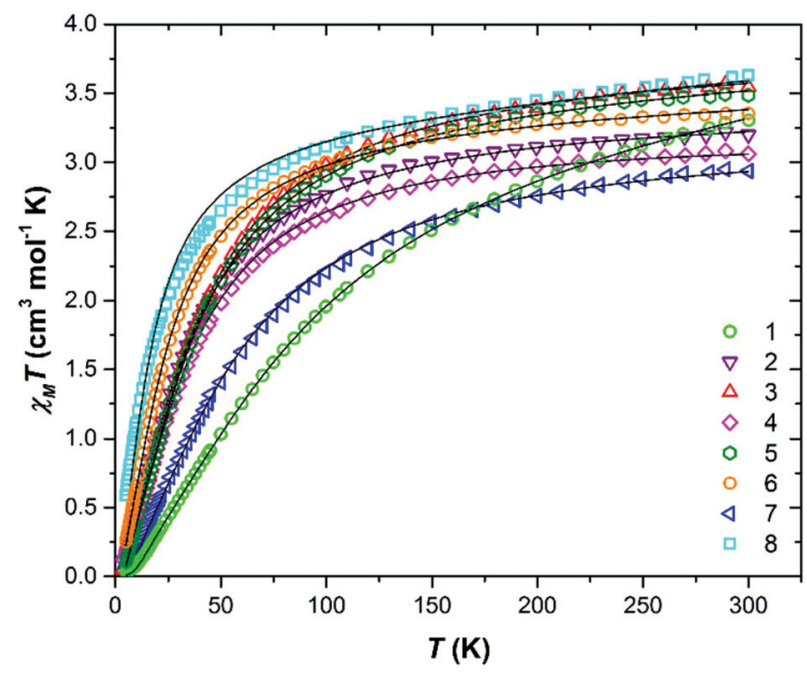

Fig. 5 Plot of the $\chi_{\mathrm{M}} T$ product versus $T$ for compounds 1-8. The solid black lines are a fit of the experimental data to spin-Hamiltonian (1). See text for full details.

Table 3 Comparison of the experimentally determined $J_{\exp }$ values of compounds $1-8$ with the theoretical $J_{\text {calc }}$ and $J_{\text {calc average }}$ values derived from DFT calculations

\begin{tabular}{lccc}
\hline Compound & $J_{\exp }\left[\mathrm{cm}^{-1}\right]$ & $J_{\text {calc average }}\left[\mathrm{cm}^{-1}\right]$ & $J_{\text {calc }}\left[\mathrm{cm}^{-1}\right]$ \\
\hline $\mathbf{1}$ & -14.13 & -12.64 & -12.64 \\
$\mathbf{2}$ & -5.37 & -3.63 & -3.63 \\
$\mathbf{3}$ & -6.23 & -4.63 & -4.63 \\
$\mathbf{4}$ & -5.77 & -6.03 & -6.56 \\
& & & -5.50 \\
$\mathbf{5}$ & -6.16 & -5.85 & -10.17 \\
$\mathbf{6}$ & & & -1.53 \\
$\mathbf{7}$ & -3.97 & -3.28 & -2.52 \\
$\mathbf{8}$ & & & -4.03 \\
& -9.35 & -9.32 & -9.32 \\
\hline
\end{tabular}

operator and $J$ is the isotropic exchange interaction parameter. This model afforded the best-fit parameters $J=-14.13$ (1), $-5.37(2),-6.23(3),-5.77(4),-6.16(5),-3.97(6),-9.35(7)$ and $-2.71(8) \mathrm{cm}^{-1}$. Table 3 lists these values together with those derived from DFT calculations for comparison (vide infra).

\section{Theoretical studies}

Theoretical studies have been carried out on complexes 1-8 in order to evaluate the magnitude and sign of the exchange parameters, and to investigate the relationship between various structural parameters. The DFT computed $J$ values for complexes 1-8 are $-12.64 \mathrm{~cm}^{-1},-3.63 \mathrm{~cm}^{-1},-4.63 \mathrm{~cm}^{-1}$, $-6.56 \mathrm{~cm}^{-1},-5.50 \mathrm{~cm}^{-1},-10.17 \mathrm{~cm}^{-1},-1.53 \mathrm{~cm}^{-1},-2.52 \mathrm{~cm}^{-1}$, $-4.03 \mathrm{~cm}^{-1},-9.32 \mathrm{~cm}^{-1},-0.67 \mathrm{~cm}^{-1}$, respectively (Table 3). All the complexes were found to exhibit antiferromagnetic exchange interactions, with the computed $J$ values reproducing both the sign and magnitude extracted from experiment.

To understand the nature of the magnetic exchange, we have analysed the overlap integrals. The dominant overlap 
integrals in all cases are found to be the $\pi\left(d_{x z}\left|p_{x}\right| d_{y z}\right)$ pairs, as shown in Fig. 6 and 7 (Tables S5-S16†). This interaction is facilitated by the $\pi\left(p_{x}\right)$ orbitals of the oxygen atoms. When the $\theta$ value is zero (Fig. 1), the $\mathrm{O}\left(\mathrm{p}_{z}\right)-\mathrm{C}\left(\mathrm{p}_{z}\right)$ sigma bonding of the bridging -OR group is perpendicular to the $\pi$ interaction described above. However, when the $\theta$ value increases, this leads to mixing of the orbitals leading to the reduction of the $\pi$ interaction and hence the overlap integrals. Since this overlap integral is monotonically dependent upon $J_{\mathrm{AF}}$, there is a reduction in the magnitude of $J$. In the extreme case, where $\theta=$ $90^{\circ}$, the sigma $\mathrm{O}-\mathrm{C}$ interactions are described by $\mathrm{O}\left(\mathrm{p}_{x}\right)-\mathrm{C}\left(\mathrm{p}_{z}\right)$ orbitals leading to the lone pairs on the O-atoms being projected along the $\left\{\mathrm{Cr}_{2} \mathrm{O}_{2}\right\}$ plane. This drastically diminishes the $\pi\left(\mathrm{d}_{x z}\left|\mathrm{p}_{x}\right| \mathrm{d}_{y z}\right)$ overlap and leads to weak ferromagnetic exchange at large $\theta$ values (Fig. 6b).

The $\mathrm{Cr}-\mathrm{O}-\mathrm{Cr}-\mathrm{O}$ dihedral $(\psi)$ angle also varies between structures, albeit only slightly. The dominant $\mathrm{d}_{x z}\left|\mathrm{p}_{x}\right| \mathrm{d}_{y z}$ overlap is expected to decrease as we move from away from a planar $\mathrm{Cr}-\mathrm{O}-\mathrm{Cr}-\mathrm{O}$ geometry $\left(\psi=0.0^{\circ}\right)$, and thus large angles would be expected to yield weaker antiferromagnetic coupling. This qualitative picture is indeed reflected in calculations where for $\psi=0.9^{\circ}$, the dominant overlap integrals are found to be $\pi\left(\mathrm{d}_{x z}\left|\mathrm{p}_{x}\right| \mathrm{d}_{y z}\right)$ pairs and this facilitates the strong antiferro- (a)

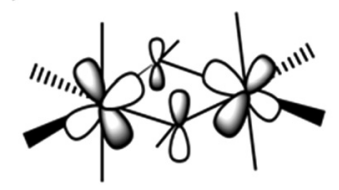

(b)

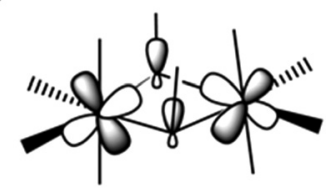

Fig. 6 Schematic representation of the $\pi\left(d_{x z}\left|p_{x}\right| d_{y z}\right)$ overlap in complex 1 when the $\theta$ is small (a) and large (b).
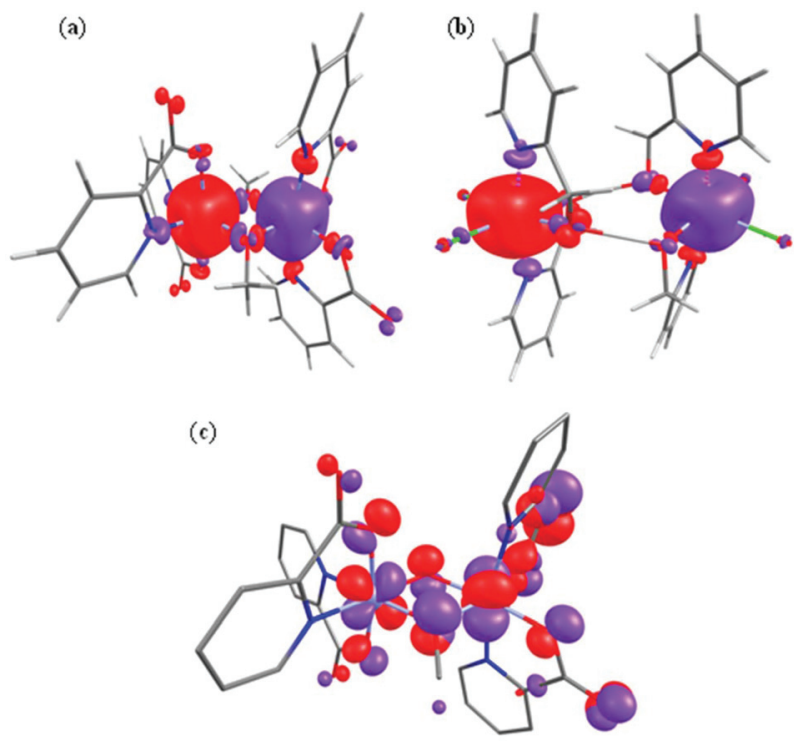

Fig. 7 Computed spin density BS1 plots for complexes 1 (a) and 8 (b). (c) The $\pi\left(d_{x z}\left|p_{x}\right| d_{y z}\right)$ overlap observed in complex 1. magnetic interaction observed. However, at $\psi=17.4^{\circ}$ the $\pi\left(\mathrm{d}_{x z}\left|\mathrm{p}_{x}\right| \mathrm{d}_{y z}\right)$ overlap integral decreases significantly and leads to weak antiferromagnetic interaction. At an angle of $\psi=27.6^{\circ}$ the exchange becomes weakly ferromagnetic.

Spin density plots computed for complexes $\mathbf{1}$ and $\mathbf{8}$ are shown in Fig. 7 (see ESI Fig. S15 and S16† for complexes 2-7). A cubic shaped spin density is observed on the $\operatorname{Cr}(\mathrm{III})$ ions, deriving from the $\mathrm{t}_{2 \mathrm{~g}}{ }^{3}$ configuration, with a dominant spin polarization mechanism operative, leading to larger than the expected spin density values at the Cr(III) centres. For complex 8, the magnetic exchange is mediated only by two $\mathrm{H}$-bonding interactions and here the dominant overlap is computed to be via $\mathrm{d}_{x z} \mid \mathrm{d}_{y z}$; as expected the magnitude of the overlap integral is small reflecting the weak AF exchange computed.

To understand the variation in the magnitude of the $J$ values, and in particular to probe if larger $\theta$ values could yield ferromagnetic exchange, magneto-structural correlations have been developed for complex 1 (Fig. 8). Our correlation affords a linear regression in $J$ with increasing $\theta$, yielding weak ferromagnetic coupling at very large $\theta$ values and strong antiferromagnetic coupling at smaller $\theta$ values. The computed overlap integrals for these points reflect the reduction in the $\pi$-type overlap as $\theta$ increases. The experimental $J$ values show a similar trend. The computed $J$ values are correlated to the overlap integrals and found to match nicely with the spin densities on the bridging oxygen atoms, with larger negative spin densities yielding stronger AF exchange (Fig. 8).

The correlation developed by DFT predicts a switch from $\mathrm{AF} \rightarrow \mathrm{F}$ exchange coupling at $\theta>47.3^{\circ}$. However, this does not match experiment (Tables 2 and 3 ), and it is clear from Fig. 8 that several complexes show experimentally determined $J$ values that deviate from this linear fit. This suggests that the $\psi$ parameter is also likely to play a key role in determining $J$. A closer look at the structures of the dimers reveals that when $\theta$ becomes larger it is accompanied by a variation in the $\psi \mathrm{di}$ -

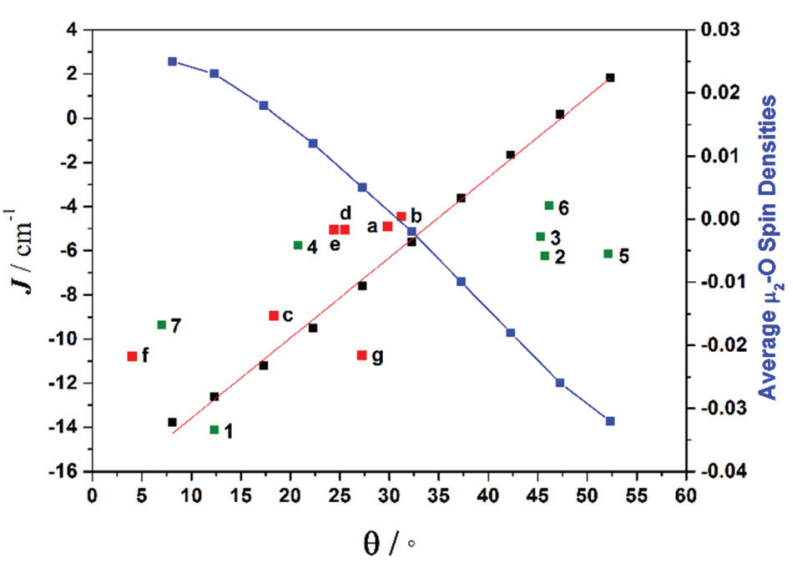

Fig. 8 Magneto-structural correlations developed by varying $\theta$ in complex 1 (black squares), along with the experimental $J$ values from compounds 1-7 (green squares), experimental $J$ values for compounds a-g from the literature (red squares) (see Table S17 $\uparrow$ for details on literature compounds), ${ }^{66-71}$ and the average bridging oxygen spin densities (blue squares). 
hedral angles, i.e. $\theta$ and $\psi$ are correlated. To ascertain the combined effect of both parameters, we have developed a magneto-structural correlation by varying both $\theta$ and $\psi$ simultaneously, with the results shown in the three dimensional plot of Fig. 9 and the contour plot of Fig. 10.

The developed correlation suggests a strong dependence of $J$ on both parameters, with the possibility of obtaining ferromagnetic exchange even with relatively small $\theta$ values, if, and only if, the corresponding $\psi$ values are relatively large. The experimentally observed $\psi$ dihedral angles are however all small, in the range $0-4.9^{\circ}$, whilst the correlation developed for $\psi$ predicts a switch from $\mathrm{AF} \rightarrow \mathrm{F}$ at angles larger than $17.4^{\circ}$. The correlation reveals that when $\psi=0^{\circ}$, varying the $\theta$ even beyond $45^{\circ}$ does not yield ferromagnetic exchange. However for $\psi=25^{\circ}, \theta$ values above $10^{\circ}$ yield ferromagnetic coupling. While the above correlations clearly establish the importance

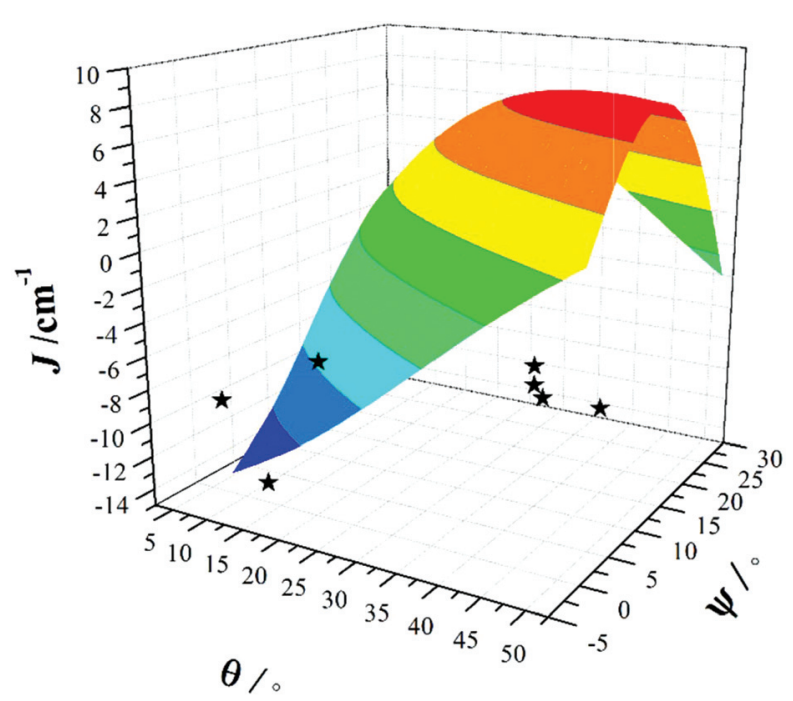

Fig. 9 Magneto-structural correlations developed by varying $\theta$ and $\psi$ simultaneously in complex 1 . The black stars are experimental $J$ values for complexes 1-7.

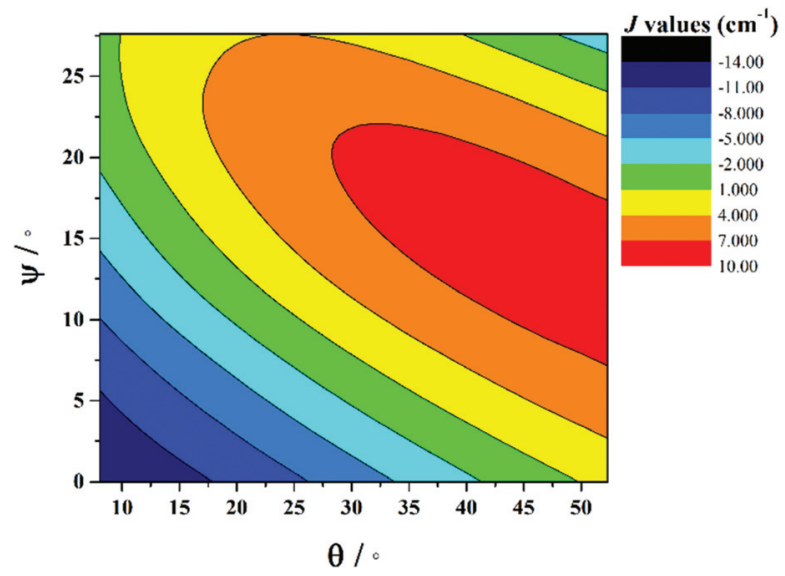

Fig. $102 \mathrm{D}$ contour plot showing the magneto-structural correlations developed by varying $\theta$ and $\psi$ simultaneously in complex 1 . of both $\theta$ and $\psi$ in controlling the magnitude of $J$, we note that calculations were limited to complex 1 where the presence of the bridging methoxide group allowed for simple alterations of both parameters independently. For complexes 2-7, where the methoxide is replaced by the alkoxide arm of the $\mathrm{hmp}^{-} / \mathrm{hep}^{-}$ ligands this is not the case, with the bridging moieties offering additional $\mathrm{Cr}(1)-\mathrm{N}-\mathrm{C}-\mathrm{C}-\mathrm{O}-\mathrm{Cr}(2)$ exchange pathways, which would likely result in minor variations in the computed magnitude of the $J$ values. Note that any attempt to vary the structural parameters in compounds 2-7 would be complicated by the knock on effect these variations would have on other structural aspects, making it impossible to isolate and study individual changes by this method.

\section{Conclusions}

The initial use of pyridine alcohol ligands in Cr(III) coordination chemistry, in the absence of any additional co-ligands, has led to the formation of a family of di-alkoxo-bridged $\left[\mathrm{Cr}_{2}(\mathrm{OR})_{2}\right]$ dimers. DC magnetic susceptibility measurements reveal weak antiferromagnetic interactions in all cases. DFT calculations reproduce the sign, magnitude and trend of the exchange coupling constants. Our developed magneto-structural correlation reveals the importance of both the angle between the $\mathrm{Cr}_{2} \mathrm{O}_{2}$ plane and the $\mathrm{O}-\mathrm{R}$ vector of the bridging group $(\theta)$ and the $\mathrm{Cr}-\mathrm{O}-\mathrm{Cr}-\mathrm{O}$ dihedral angles $(\psi)$ in modulating the sign and strength of $J$.

\section{Acknowledgements}

EKB thanks the EPSRC for funding. GR would like to thank the DST (no. EMR/2014/000247) for funding. GV would like to thank Indian Institute of Technology, Bombay for a Postdoctoral Fellowship.

Data can be found in the depository Edinburgh DataShare http://datashare.is.ed.ac.uk/.

\section{Notes and references}

1 S. M. Gorun, G. C. Papaefthymiou, R. B. Frankel and S. J. Lippard, J. Am. Chem. Soc., 1987, 109, 3337-3348.

2 R. Bagai and G. Christou, Chem. Soc. Rev., 2009, 38, 10111026.

3 A. Caneschi, D. Gatteschi, R. Sessoli and P. Rey, Acc. Chem. Res., 1989, 22, 392-398.

4 S. Srinivasan and R. Seshan, in Chromium -VI Reagents: Synthetic Applications, Springer, Berlin, Heidelberg, 2011, pp. 63-66, DOI: 10.1007/978-3-642-20817-1_6.

5 I. Mulyani, A. Levina and P. A. Lay, Angew. Chem., Int. Ed., 2004, 43, 4504-4507.

6 R. D. Cannon and R. P. White, Prog. Inorg. Chem., 1988, 36, 195-298. 
7 E. J. McInnes, G. A. Timco, G. F. Whitehead and R. E. Winpenny, Angew. Chem., Int. Ed., 2015, 54, 1424414269.

8 E. J. L. McInnes, S. Piligkos, G. A. Timco and R. E. P. Winpenny, Coord. Chem. Rev., 2005, 249, 25772590.

9 B. N. Figgis and G. B. Robertson, Nature, 1965, 205, 694695.

10 R. F. Weinland, Ber. Dtsch. Chem. Ges., 1908, 41, 32363245.

11 A. Werner, Ber. Dtsch. Chem. Ges., 1908, 41, 3447-3465.

12 T. Fujihara, J. Aonahata, S. Kumakura, A. Nagasawa, K. Murakami and T. Ito, Inorg. Chem., 1998, 37, 3779-3784.

13 S. Parsons, A. A. Smith and R. E. P. Winpenny, Chem. Commun., 2000, 579-580.

14 A. Ghirri, J. van Tol, I. Vitorica-Yrezabal, G. A. Timco and R. E. Winpenny, Dalton Trans., 2015, 44, 14027-14033.

15 P. Koegerler, B. Tsukerblat and A. Mueller, Dalton Trans., 2010, 39, 21-36.

16 T. Ellis, M. Glass, A. Harton, K. Folting, J. C. Huffman and J. B. Vincent, Inorg. Chem., 1994, 33, 5522-5527.

17 A. Bino, D. C. Johnston, D. P. Goshorn, T. R. Halbert and E. I. Stiefel, Science, 1988, 241, 1479-1481.

18 I. M. Atkinson, C. Benelli, M. Murrie, S. Parsons and R. E. P. Winpenny, Chem. Commun., 1999, 285-286.

19 M. Eshel, A. Bino, I. Felner, D. C. Johnston, M. Luban and L. L. Miller, Inorg. Chem., 2000, 39, 1376-1380.

20 E. J. L. McInnes, C. Anson, A. K. Powell, A. J. Thomson, S. Poussereau and R. Sessoli, Chem. Commun., 2001, 89-90.

21 M. Eshel and A. Bino, Inorg. Chim. Acta, 2002, 329, 45-50.

22 J. van Slageren, R. Sessoli, D. Gatteschi, A. A. Smith, M. Helliwell, R. E. P. Winpenny, A. Cornia, A.-L. Barra, A. G. M. Jansen, E. Rentschler and G. A. Timco, Chem. Eur. J., 2002, 8, 277-285.

23 P. Christian, G. Rajaraman, A. Harrison, J. J. W. McDouall, J. T. Raftery and R. E. P. Winpenny, Dalton Trans., 2004, 1511-1512.

24 D. M. Low, G. Rajaraman, M. Helliwell, G. Timco, J. van Slageren, R. Sessoli, S. T. Ochsenbein, R. Bircher, C. Dobe, O. Waldmann, H. U. Gudel, M. A. Adams, E. Ruiz, S. Alvarez and E. J. L. McInnes, Chem. - Eur. J., 2006, 12, 1385-1396.

25 A. S. Batsanov, G. A. Timko, Y. T. Struchkov, N. V. Gerbeleu and K. M. Indrichan, Koord. Khim., 1991, 17, 662-669.

26 F. E. Mabbs, E. J. L. McInnes, M. Murrie, S. Parsons, G. M. Smith, C. C. Wilson and R. E. P. Winpenny, Chem. Commun., 1999, 643-644.

27 C. E. Talbot-Eeckelaers, G. Rajaraman, J. Cano, G. Aromi, E. Ruiz and E. K. Brechin, Eur. J. Inorg. Chem., 2006, 33823392.

28 R. Shaw, R. H. Laye, L. F. Jones, D. M. Low, C. TalbotEeckelaers, Q. Wei, C. J. Milios, S. Teat, M. Helliwell, J. Raftery, M. Evangelisti, M. Affronte, D. Collison, E. K. Brechin and E. J. L. McInnes, Inorg. Chem., 2007, 46, 4968-4978.

29 A. Døssing, Coord. Chem. Rev., 2014, 280, 38-53.
30 N. H. Andersen, A. Dossing and A. Molgaard, Inorg. Chem., 2003, 42, 6050-6055.

31 J. Glerup and H. Weihe, Inorg. Chem., 1997, 36, 2816-2819.

32 B. G. Gafford, R. A. Holwerda, H. J. Schugar and J. A. Potenza, Inorg. Chem., 1988, 27, 1126-1128.

33 T. F. Tekut, C. J. O'Connor and R. A. Holwerda, Inorg. Chem., 1993, 32, 324-328.

34 T. J. Morsing, J. Bendix, H. Weihe and A. Dossing, Inorg. Chem., 2014, 53, 2996-3003.

35 R. A. Holwerda, T. F. Tekut, B. G. Gafford, J. H. Zhang and C. J. O'Connor, J. Chem. Soc., Dalton Trans., 1991, 10511055.

36 D. J. Hodgson, M. H. Zietlow, E. Pedersen and H. Toftlund, Inorg. Chim. Acta, 1988, 149, 111-117.

37 D. M. Stearns and W. H. Armstrong, Inorg. Chem., 1992, 31, 5178-5184.

38 T. Fujihara, A. Fuyuhiro and S. Kaizaki, J. Chem. Soc., Dalton Trans., 1995, 1813-1821.

39 A. Drljaca, D. C. R. Hockless, B. Moubaraki, K. S. Murray and L. Spiccia, Inorg. Chem., 1997, 36, 1988-1989.

40 G. Novitchi, J. P. Costes, V. Ciornea, S. Shova, I. Filippova, Y. A. Simonov and A. Gulea, Eur. J. Inorg. Chem., 2005, 5, 929-937.

41 J. Glerup, P. A. Goodson, D. J. Hodgson, M. A. Masood and K. Michelsen, Inorg. Chim. Acta, 2005, 358, 295-302.

42 J. Glerup, D. J. Hodgson and E. Pedersen, Acta Chem. Scand. Ser. A, 1983, 37, 161-164.

43 T. J. Morsing, H. Weihe and J. Bendix, Eur. J. Inorg. Chem., 2014, 2014, 5990-5996.

44 M. Ardon, A. Bino, K. Michelsen and E. Pedersen, J. Am. Chem. Soc., 1987, 109, 5855-5856.

45 P. A. Goodson, J. Glerup, D. J. Hodgson, K. Michelsen and U. Rychlewska, Inorg. Chem., 1994, 33, 359-366.

46 G. M. Sheldrick, Acta Crystallogr., Sect. C: Cryst. Struct. Commun., 2015, 71, 3-8.

47 O. V. Dolomanov, L. J. Bourhis, R. J. Gildea, J. A. K. Howard and H. Puschmann, J. Appl. Crystallogr., 2009, 42, 339-341.

48 M. J. Frisch, G. W. Trucks, H. B. Schlegel, G. E. Scuseria, M. A. Robb, J. R. Cheeseman, G. Scalmani, V. Barone, B. Mennucci, G. A. Petersson, H. Nakatsuji, M. Caricato, X. Li, H. P. Hratchian, A. F. Izmaylov, J. Bloino, G. Zheng, J. L. Sonnenberg, M. Hada, M. Ehara, K. Toyota, R. Fukuda, J. Hasegawa, M. Ishida, T. Nakajima, Y. Honda, O. Kitao, H. Nakai, T. Vreven, J. A. Montgomery Jr., J. E. Peralta, F. Ogliaro, M. Bearpark, J. J. Heyd, E. Brothers, K. N. Kudin, V. N. Staroverov, R. Kobayashi, J. Normand, K. Raghavachari, A. Rendell, J. C. Burant, S. S. Iyengar, J. Tomasi, M. Cossi, N. Rega, J. M. Millam, M. Klene, J. E. Knox, J. B. Cross, V. Bakken, C. Adamo, J. Jaramillo, R. Gomperts, R. E. Stratmann, O. Yazyev, A. J. Austin, R. Cammi, C. Pomelli, J. W. Ochterski, R. L. Martin, K. Morokuma, V. G. Zakrzewski, G. A. Voth, P. Salvador, J. J. Dannenberg, S. Dapprich, A. D. Daniels, O. Farkas, J. B. Foresman, J. V. Ortiz and J. Cioslowski and D. J. Fox, GAUSSIAN 09 (Revision A.02), Gaussian, Inc., Wallingford, CT, 2009. 
49 A. D. Becke, J. Chem. Phys., 1993, 98, 5648-5652.

50 A. Schafer, H. Horn and R. Ahlrichs, J. Chem. Phys., 1992, 97, 2571-2577.

51 A. Schafer, C. Huber and R. Ahlrichs, J. Chem. Phys., 1994, 100, 5829-5835.

52 M. Atanasov, P. Comba, S. Hausberg and B. Martin, Coord. Chem. Rev., 2009, 253, 2306-2314.

53 L. Noodleman, J. Chem. Phys., 1981, 74, 5737-5743.

54 W. P. Barros, R. Inglis, G. S. Nichol, T. Rajeshkumar, G. Rajaraman, S. Piligkos, H. O. Stumpf and E. K. Brechin, Dalton Trans., 2013, 42, 16510-16517.

55 N. Berg, T. Rajeshkumar, S. M. Taylor, E. K. Brechin, G. Rajaraman and L. F. Jones, Chem. - Eur. J., 2012, 18, 5906-5918.

56 P. Comar, T. Rajeshkumar, G. S. Nichol, M. B. Pitak, S. J. Coles, G. Rajaraman and E. K. Brechin, Dalton Trans., 2015, 44, 19805-19811.

57 M. A. Bolcar, S. M. J. Aubin, K. Folting, D. N. Hendrickson and G. Christou, Chem. Commun., 1997, 1485-1486.

58 E. K. Brechin, E. C. Sanudo, W. Wernsdorfer, C. Boskovic, J. Yoo, D. N. Hendrickson, A. Yamaguchi, H. Ishimoto, T. E. Concolino, A. L. Rheingold and G. Christou, Inorg. Chem., 2005, 44, 502-511.

59 E. K. Brechin, M. J. Knapp, J. C. Huffman, D. N. Hendrickson and G. Christou, Inorg. Chim. Acta, 2000, 297, 389-399.

60 E. C. Yang, W. Wernsdorfer, S. Hill, R. S. Edwards, M. Nakano, S. Maccagnano, L. N. Zakharov, A. L. Rheingold,
G. Christou and D. N. Hendrickson, Polyhedron, 2003, 22, 1727-1733.

61 E. C. Yang, D. N. Hendrickson, W. Wernsdorfer, M. Nakano, L. N. Zakharov, R. D. Sommer, A. L. Rheingold, M. Ledezma-Gairaud and G. Christou, J. Appl. Phys., 2002, 91, 7382-7384.

62 J. Moncol, K. Jomova, L. Zelenicky, T. Lis and M. Valko, Acta Crystallogr., Sect. C: Cryst. Struct. Commun., 2011, 67, M318-M320.

63 T. J. Boyle, L. A. M. Ottley, M. A. Rodriguez, R. M. Sewell, T. M. Alam and S. K. McIntyre, Inorg. Chem., 2008, 47, 10708-10717.

64 B. Muller, A. Schneider, M. Tesmer and H. Vahrenkamp, Inorg. Chem., 1999, 38, 1900-1907.

65 R. J. Fites, A. T. Yeager, T. L. Sarvela, W. A. Howard, G. Zhu and K. L. Pang, Inorg. Chim. Acta, 2006, 359, 248-256.

66 H. R. Fischer, J. Glerup, D. J. Hodgson and E. Pedersen, Inorg. Chem., 1982, 21, 3063-3066.

67 H. R. Fischer, D. J. Hodgson and E. Pedersen, Inorg. Chem., 1984, 23, 4755-4758.

68 E. D. Estes, R. P. Scaringe, W. E. Hatfield and D. J. Hodgson, Inorg. Chem., 1977, 16, 1605-1610.

69 E. D. Estes, R. P. Scaringe, W. E. Hatfield and D. J. Hodgson, Inorg. Chem., 1976, 15, 1179-1182.

70 B. Liu, J. Chai, S. S. Feng and B. S. Yang, Spectrochim. Acta, Part A, 2015, 140, 437-443.

71 N. Clement, C. Toussaint, G. Rogez, C. Loose, J. Kortus, L. Brelot, S. Choua, S. Dagorne, P. Turek and R. Welter, Dalton Trans., 2010, 39, 4579-4585. 